\title{
Dynamics of Formal Seed Utilization and Use Intensity: Evidence from Wheat Growers in East Gojjam Province, North-western Ethiopia
}

\author{
Amare Tesfaw \\ Debre Markos University, College of Agriculture and Natural Resources, Department of Agricultural Economics, Debre Markos, Ethiopia
}

Email address:

yordanoseyuel@gmail.com

To cite this article:

Amare Tesfaw. Dynamics of Formal Seed Utilization and Use Intensity: Evidence from Wheat Growers in East Gojjam Province, Northwestern Ethiopia. International Journal of Business and Economics Research. Vol. 4, No. 3, 2015, pp. 86-97.

doi: $10.11648 /$ j.ijber.20150403.12

\begin{abstract}
Commercial agriculture is driven by utilization of modern agricultural inputs despite the variable rate of adoption and use intensity. This study investigates the major factors attributed to variation in households' participation and intensity of formal seed useby taking 4 districts as a case in East Gojjam, Northwestern Ethiopia. A total of 250 farmers were selected following 3 stages and data were processed with Heckman Two-Stage Model using STATA (version 13). The result showed that households participation in formal seed use was significantly affected by land allocated for wheat and the number of oxen (positively, $\mathrm{P}<0.01$ ), farming experience (positively, $\mathrm{P}<0.1$ ) and age and off-farm income (negatively, $\mathrm{P}<0.01$ and $\mathrm{P}<0.05$ respectively). Similarly, intensity of formal seed utilized was significantly influenced by size of wheat land, number of oxen and frequency of extension services (positively, $\mathrm{P}<0.01$ ) and sex and family size (positively, $\mathrm{P}<0.05$ ). The existing seed supply chains are inefficient, seed systems are institutionalized and there are weak initiatives for community based seed systems. Strong extension services, empowering females with financial incentives and encouraging farmer based seed multiplication system can improve farmers' tendency of improved seed use. Rapid intervention on monopolistic distribution of seeds can bring about competitive seed markets which lead to sufficient supply with optimum prices.
\end{abstract}

Keywords: Cooperatives, Ethiopia, Formal Seed System, Heckman, Intensity, Supply Chains

\section{Introduction}

\subsection{Background}

Recent strategies of economic development give increasing attention to the need for significant improvements in agricultural productivity in order to achieve food security and poverty reduction goalsin particular and economic development in general. Much of the research on African agriculture demonstrates that farmers' failure to intensify agricultural production is a key component of inefficiency and lower productivity (Crawfordet al., 2006).

Smallholder farmers share several characteristics in common including being seasonal producers, fragmented buyers and suppliers, they are unable to exploit economies of scale. These farmers (especially in the rain fed areas) are faced with constraints in the production process, access to inputs and credit and marketing and value additions. The production level of these smallholder farmers is further constrained by their small landholdings, weaknesses in the land tenure system and unequal access to irrigation water. Furthermore, they face difficulty in procuring and applying modern technologies due to the high costs and greater risks associated with new technologies (IFPRI, 2011).

As major agricultural inputs, seeds form the foundation of all types of crop production without which there is no next season's crop. The genotypic and phenotypic traits of seed determine the productivity in line with the use of other agricultural inputs and improved cultural practices within the farming system. Improving the genetic and physical properties of seed can trigger yield increase and lead to improvement in the agricultural production and food security. In order to strengthen the performance of seed in crop production, there is always a need to use new and improved seed varieties which can be supplied by different supplying organizations. This improved seed has to be made sustainably available for all farmers as they significantly improve farmers' income and alleviate poverty. Many farmers still fail 
to access these improved seeds from the nearby retail markets as many of the released varieties have never been widely distributed and made available (Rohrbach et al., 2002; Baffour et. el., 2014).

Crop improvement is a key area of agricultural research, which involves selective breeding to identify and develop crop varieties, promoting these varieties and associated management strategies through extension and providing seed (and other inputs) through supply systems. The absence of effective formal seed system greatly reduces the smooth functioning of publicly funded plant breeding programs. This failure of efficient seed multiplication and distribution is translated in to negative rate of return to research investment (Chapman and Tripp, 2003).

Seed systems can be either formal or informal/local. Formal systems generally consist of public sector research institutions, public and private sector agencies producing and marketing seed and organizations responsible for seed certification and quantity control. Due to lack of proper organizational set up, inadequacy in trained manpower and limited private participation, the formal seed sector has not developed as expected (Yonas, 2012; Bortei-Doku Aryeetey, 1994).The informal system consists of large number of farmers who produce both traditional and modern varieties, market their own production, and take care of their own research needs (Setimela et. al, 2006).

\subsection{Statement of the Problem}

Most Ethiopian farmers are seasonal producers of grains and cereals. East Gojjam province is one of such areas inhabited by farmers who use rain fed agriculture to produce different crops in farm lands that require relatively higher amount of modern agricultural inputs.According to the East Gojjam province Agricultural office report, the present status of the land exhibits marginal productivitycharacteristics due to frequent land degradationfollowing intensive agricultural practices.

Despite the intensive requirement of agricultural inputs for the production land, many farmers tend to use informal seed supply system.According to the 2013 East Gojjam province Agricultural Office report, the utilization of improved seed supply concerning major crops was found to bewheat (2,608.4 tonne), maize (766.7tonne), teff (246.4 tonne) and barley (70.2 tonne). The report revealed that of the total of 361,326 producer household heads, only 178,157 farmer households' utilized improved seeds, which is less than half of the total of producing households. The advantage that many farmers lose due to failure to use formal seed supply system (improved seeds that may be supplied by many supplying companies) or the opportunity cost can be compensated by implementing the utilization of formal seed supply together with other modern agricultural inputs.

In order to improve farmers output and ultimately their livelihood through creating the access to improved seeds in East Gojjam province, it is essential to study the exact factors affecting the utilization of formal seed supply system and estimate the intensity of seeds utilized from the formal seed supply system. In addition, it is also important to examine the different seed multiplication and distribution channels together with different market linkages.

The study wasaimed to examine the utilization offormal seeds in East Gojjam regarding seed multiplication, distribution and market linkages.

The specific objectives were to:

1) Identify factors that affect utilization of formal seeds

2) Determine the amount of formal seeds utilized

3) Investigate the different market linkages and formal seed supply systems and

4) Examine formal seed production and distribution systems

\section{Methodology}

\subsection{Description of the Study Area}

East Gojjam Administrative Province is one of the 11Administrative Provinces of the Amhara National Regional State. Debre Markos, which is the capital city of the province, is located $37^{\circ} 44^{\prime} 53^{\prime \prime}$ Elongitude and $10^{\circ} 18^{\prime} 10^{\prime \prime} \mathrm{N}$ latitude. It is located $300 \mathrm{kms}$ Northwest of Addis Ababa.East Gojjam Province has18 districts which are categorized based on different agro ecological and socio-demographic characteristics.

\subsection{Data Types and TheirSources}

Both primary and secondary data sources were used for the study. Primary data were gathered from farmers, extension workers, concerned government officials and non government bodies. Secondary data sources include bureau of agriculture and rural development and agricultural cooperatives.

\subsection{Sample Size and Sampling Design}

There is a contradiction among researchers on sampling procedures and sampling size that are used in marketing study. The decisions involved on sampling procedures and the sample size to be taken are partly functions of the currently available information, time and other resources available, accessibility and openness of the marketing participants themselves as well as the estimated.

In order to generate primary data, a pre-tested questionnaire was administered on 250 farmers that were selected following 3 stages. In the first stage, 4districtswere selected purposively out of the 18.In the second stage, based on proportion of population respondents,KA's were selected randomly from each districtand the number of household respondents was proportionately determined to have a total of 250 sample sizes.Checklists and group discussions with key informants werealso employed in order to acquire supplementary information.

\subsection{Methods of Data collection}

Interviewing schedulewere prepared and tested prior to the 
actual data collection for farmers and formal seed suppliers.

\subsection{Methods of Data Analysis}

Both descriptive statistics and econometric analysis (Heckman Two Stage Model) were used for the analysis of the data obtained from the survey.

\subsubsection{Descriptive Statistics Analysis}

Themeans, percentages, variances and standard deviations were used to examine households' socio-economic characteristics.Chi-square $\left(\chi^{2}\right)$ and t-testswere used to test dummy and continuous variables respectively.

\subsubsection{Econometric Model Specification}

The use of OLS estimation leads to inconsistent and biased estimate results if the dependent variable is limited in its range (as the values of dependent variables which are censored at zero pose self selection problems) when econometric models like Tobit are used. In order to overcome this self selection problem, Heckman two stage estimation procedure issuggested to be the best estimation method.

Farmers'participation for the supply of formal seeds is a dummy variable thattakes a value of 1 if the household head is willing and 0 otherwise.

The model is structured as follows:

1. The probability of a household's head to participate in taking formal seed useis given by the selection equation as:

$$
Y_{i}=\beta i X_{i}+\varepsilon i,
$$

Where $_{\mathrm{i}} \sim N(0,1), \mathrm{i}=1,2, \ldots, \mathrm{n}$.

$\mathrm{Y}_{\mathrm{i}}=\mathrm{A}$ dummy variable that takes a value of 1 if a household's head has participatedand 0 otherwise

$\beta_{i}=$ Vector parameter

$\mathrm{X}_{\mathrm{i}}=$ Parameters to be estimated in the model

$\varepsilon_{\mathrm{i}=}$ Error term and it is normalized to 1 since a farmer who participated is observed and it is assumed to be bivariate, and normally distributed (with correlationcoefficient, $\rho$ )

2. The amount (intensity) of formal seed utilized isexpressedusing the followingequation by including an estimate of the inverse Mill's Ratio $\left(\lambda_{\mathrm{j}}\right)$ as:

$$
Y_{j}=\beta_{j} X_{j}+\lambda_{j} \mu+\varepsilon_{j}
$$

where $\varepsilon_{j} \sim \mathrm{N}\left(0, \delta^{2}\right)$

$\mathrm{Y}_{\mathrm{j}}=$ the amount of utilized formal seed supplyand observed if only participation isyes, that is $\mathrm{Y}_{\mathrm{j}}=1$

$\beta_{\mathrm{j}}=$ Unknown parameter to be estimated in the outcome equation

$\chi_{\mathrm{j}}=$ Explanatory variable that can affect the utilization of formal seed supply

$\lambda=$ A correction factor for selection bias (Invers Mill's Ratio)

$\varepsilon_{\mathrm{j}}=$ Error term, this is assumed to be bivariant, and normally distributed withcorrelation coefficient, $\delta^{2}$ )

The inverse mills ratio $(\lambda)$ is a variable for controlling bias due to sample selection. Thus, the Heckman second stage accounts the mills ratio to the outcome equation(amount of utilized seed)using OLS estimates (Heckman, 1979).

Variance Inflation Factor (VIF) was used to check the existence of multicolinearity among continuous variables (Gujarat, 2003). Before fitting important variables in the model it was necessary to test multi co linearity problem among continuous variables and check associations among discrete variablesas highly affect the parameter estimates. The larger the value of VIF is greater than 10 (this will happen if $\mathrm{R}^{2}$ is greater than 0.80 ) the variable is said to be highly collinear.

$$
\operatorname{VIF}\left(\chi_{\mathrm{j}}\right)=\left(1-\mathrm{R}_{j}^{2}\right)^{-1}
$$

Where, $\mathrm{R}_{j}^{2}$ is the multiple correlation coefficients between explanatory variables, the larger the value of $\mathrm{R}_{j}^{2}$, the higher the value of VIF $\left(\chi_{\mathrm{j}}\right)$ causing co linearity in the variable $\left(\chi_{\mathrm{j}}\right)$.

The multi co linearity between discrete variables were calculated using contingency coefficient the values ranging between 0 and 1, with 0 indicating no association between the variables and value close to 1 indicating a high degree of association between variables.

$$
C C=\sqrt{\frac{\chi^{2}}{N+\chi^{2}}}
$$

WhereCC-contingency coefficient, $\chi^{2-}$ Chi-square test and

$N$-Total sample size.

If the value of $\mathrm{CC}$ is greater than 0.75 , the variables are said to be collinear.

\subsection{Hypothesis, Variables Formulations and Their Definition}

\subsubsection{Dependent (Explained) Variables}

Participation for utilization of formal seed supply

It is dependent dummy variable in the first stage of Heckman two stage estimation procedures that is regressed. The variable has value one if the respondent iswilling to pay and zero otherwise.

Amount of seed utilized (SEED_USED)

It is dependent continues variable estimated in the second stage of Heckman two stage model. It represents the amount of seed utilized in kilogram.

\subsubsection{Independent (Explanatory) Variables}

Land size (LAND)

This is the total plot size (ha) allocated for improved wheat production in 2013 production season and it is expected to be positively associated with the decision to adopt improved seed production technologies and the amount of seed utilized. This means that farmers who have relatively bigger plots will have a great tendency to have the options of paying for the formal seed supply and this variable is hypothesized to have positive effect on both participation and amount of formal seeds to be utilized.

Total livestock ownership (TLU)

This refers to the total number of animals possessed bythe household measured in tropical livestock unit (TLU). 
Farmers who possess more number of cattle are assumed to have potential to pay more for the formal seed supply and use intensively.

Income from farming activities (FARINC)

This the income earned from farming activities in 2013 production season. It is hypothesized that this variable can positively affect both the utilization and intensity of use of formal seeds.

Farming experiences (FAREXP)

It is measured in the categorized number of years since arespondent started farming on his own. Experience of the farmers is likely to have a range ofinfluences on adoption. Experience expected to improve farmers' involvement in formal seed supply utilization.

Distance from the main road (DISTRD)

It is a continuous variable measured in kilometer. It refers to the distance from farmers home to the main all weather roads. As farmers' home gets closer to the main road, they can have access to transportation facilities and relatively better support from concerned bodies for the formal seed supply and thus it will have positive relationship with the utilization of formal seeds.

Age of household head (AGE)

It is a continuous variable and measured in years, which refers to the number of years the farmer engaged in pepper production. Thus there exists a positive relationship between the variable and the formal seed supply utilization.

Number of Oxen (OXEN)

Oxenare important means of production in agriculture and thus oxen ownership and adoption are expected to relate positively with the dependent variables.

Sex of the households head (SEX)

This is dummy variable that takes a value of 1 if the household head is male and 0 otherwise and expected to have positive relationship with both participation and amount of seed to be utilized.

Education level of the household (EDUC)

This is a categorical variable is measured using by assigning values beginning from 0 (for illiterate ones). The higher the education level, the better would be his attitude in adopting new technologies. It is expected that those farmers with higher formal education are more likely to involve and participate in utilization of formal seed utilization.

Frequency of extension contact (EXTN)

The variable was measured as continuous taking values greater than or equal to 0 . Farmers who have a frequent contact with extension agents are expected to accept and practice new ideas faster than those farmers who had few contacts. Hence, the frequency of contact with extension agent is assumed to have direct relation with participation and intensity of seeds to be utilized.

Off-farm income (OFFINC)

It is a continuous variable that represents part of the total amount of income measured in birr that is earned from nonagricultural activities. This additional income increases the farmers' financial capacity and is expected to increase the probability of investing in new technologies. Hence, availability of off-farm income is hypothesized to be one of the factors that influence the dependent variables positively.

Access to credit (ACRDT)

This is a dummy variable taking value of 1 if the farmer has access to credit and 0 otherwise. Access to credit would enhance the financial capacity of the farmer to purchase the necessary inputs. Therefore, it is hypothesized that access to credit will have positive influence on participation and volume of seeds to be utilized.

\section{Results and Discussion}

\subsection{Demographic Characteristics of Sample Households}

Various factors were found to significantly affect household heads' participation in formal seed utilization and the volume of formal seeds utilized. Among the factors that broughtsignificant disparity include socioeconomic variables like age, family size, sex and education level of households (Table 1).

The result indicated that significant $(\mathrm{P}<0.01)$ difference in age resulted variation in technology adoption and production potentials among households in different districts. Similarly, there was a significant $(\mathrm{P}<0.05)$ difference in family size among farmers across districts which in turn brought differences in formal seed utilization adoption and utilization and other farming activities.

Table 1. Demographic characteristics of sample households among districts.

\begin{tabular}{|c|c|c|c|c|c|c|c|}
\hline Districts & & Debre Elias & Baso Liben & Gozamen & Machakel & Total & F/ $\chi^{2}$ Value \\
\hline Age & & $39.93(9.14)$ & $41.40(10.50)$ & $43.35(9.75)$ & $46.09(9.76)$ & $42.71(10.01)$ & $4.62 * * *$ \\
\hline Family size & & $5.43(2.82)$ & $5.39(2.06)$ & $4.41(1.95)$ & $4.93(2.43)$ & $4.93(2.43)$ & $3.36 * *$ \\
\hline $\operatorname{Sex}(\%)$ & $\begin{array}{l}\text { Male } \\
\text { Female }\end{array}$ & $\begin{array}{l}95.16 \\
4.84\end{array}$ & $\begin{array}{l}11.29 \\
88.71\end{array}$ & $\begin{array}{l}11.11 \\
88.89\end{array}$ & $\begin{array}{l}121.70 \\
87.30\end{array}$ & $\begin{array}{l}10 \\
90\end{array}$ & 2.54 \\
\hline
\end{tabular}

Note: Values in parenthesis are standard deviations

$* *$ and $* * *=$ Significant at $\mathrm{P}<0.05$ and $\mathrm{P}<0.01$ respectively

Source: Survey result, 2014.

The sample households' age and family size statistics indicated that there was a significant $(\mathrm{P}<0.01)$ mean difference among users and non users of formal seeds (Table
2). The variation in age among the two categories of households indicates that human productivity potential is highly age dependent (the younger being more productive 
than the elderly). Family is the main source of labor for the farming community. The survey result indicated significant difference in family size between improved seed user and non-user groups of the sample households.

Table 2. Age and family size dynamics among formal seed users and non-users.

\begin{tabular}{llll}
\hline Variables & Formal seed users & Non-users & F/ $\chi^{2}-$ Value \\
\hline Age & $41.14(9.60)$ & $51.76(7.21)$ & $7.13^{* * *}$ \\
Family size & $5.40(2.30)$ & $2.19(0.81)$ & $39.00^{* * *}$ \\
ExtensionFrequency $(\%)$ & 85.20 & 14.80 & $19.08^{* * *}$ \\
\hline
\end{tabular}

Note: Values in parenthesis are standard deviations

$* * *=$ Significant at $\mathrm{P}<0.01$

Source: Survey result, 2014.

Significant $(\mathrm{P}<0.01)$ difference between user and non-user households were observed in the frequency of extension service delivery which in turn resulted in disparity in adoption as well as the amount of the formal seed utilized (Table 2). However, there was no significant education background difference among districts or between user and non-user groups of households heads (Table 3).

There was no significant difference between users and nun-user groups because of the variation in the number of years of farming experience. This is because due to extensive extension services, almost all farmers have more or less similar practical exposure in implementing agricultural packages. In adoption study of wheat and maize in Yilmana
Densa and Farta districts, a similar finding was reported by Tesfaye et. al., (2001) that there was no significant difference between adopter and non-adopter farmers due to variation in farming experience.The extent to which the formal seed system is adopted by producer farmers is also a function of the degree to which farmers are introduced and exposed to the extension packages and the frequency of extension contact. As depicted in Table 2, there was a significant difference in frequency of extension service among user and non user groups. In a market study, Tesfaw (2013) found significance difference in intensity of market supply due to differences in access to extension services.

Table 3. Education levels of households among districts.

\begin{tabular}{llllll}
\hline & & Debre Elias & Baso Liben & Gozamen & Machakel \\
\hline & Illiterate & 14.52 & 16.13 & 15.87 & 17.46 \\
& Read and write & 27.42 & 32.26 & 26.98 & 33.33 \\
& Grade 1-4 & 24.19 & 9.68 & 25.40 & 9.52 \\
Education Level (\%) & Grade 5-6 & 22.58 & 17.74 & 17.46 & 17.46 \\
& Secondary school & 8.06 & 19.35 & 11.11 & 17.46 \\
& Certificate and above & 3.23 & 4.84 & 3.17 & 4.76 \\
\hline
\end{tabular}

Source: Survey result, 2014

\subsection{Socio-Economic Characteristics of Sample Households}

Plot size dynamics among user groups of households showed variations across districts. Information obtained from key informants and field observation revealed that farmers who possess bigger plots use multiple cropping systems better than those who have relatively smaller plot sizes. This indicates that farmers who apply multiple cropping have a great propensity of adoption of improved seeds better than landless households or those possessing small plots. The smaller the plot size a farmer owns, the greater will be the chance to cover that plot with mono cropping.

Table 4. Land holding and farming income of formal seed users and non-users.

\begin{tabular}{llll}
\hline Variables & Formal seed users & Non-users & F/ $\chi^{2}$-Value \\
\hline Income from crop (ETB) & $16,791.55(6,813.01)$ & $12,394.59(5,906.16)$ & $2.07 * *$ \\
Income from livestock(ETB) & $7,466.15(9,931.06)$ & $10,660.81(19697.06)$ & $11.85 * * *$ \\
Off-farm income (ETB) & $1,345.54(2,678.79)$ & $5,371.35(4,534.52)$ & $47.00 * * *$ \\
\hline
\end{tabular}

Note: Values in parenthesis are standard deviations. The 2014 exchange rate of 1ETB is 19USD.

$* * *$ and ** represent levels of significance at $\mathrm{P}<0.01$ and $\mathrm{P}<0.05$ respectively

Source: Survey result, 2014.

Significant differences were observed in level of income from different sources among user and non user households. The level of income received by households from crop was significantly different between improved user and non-user farmers. This is because, the variation in land size, productivity of plots and level of extension contact resulted 
in product variation.

The amount of income from livestock was quite different and significant between user and non-user groups. As seen in Table 4, on average this income was 7,466.15ETB and for non-users, it is $10,660.81 \mathrm{ETB}$. The reason for this income difference may be attributed to involvement of non-users in livestock rearing and fattening activities more than that of user households.

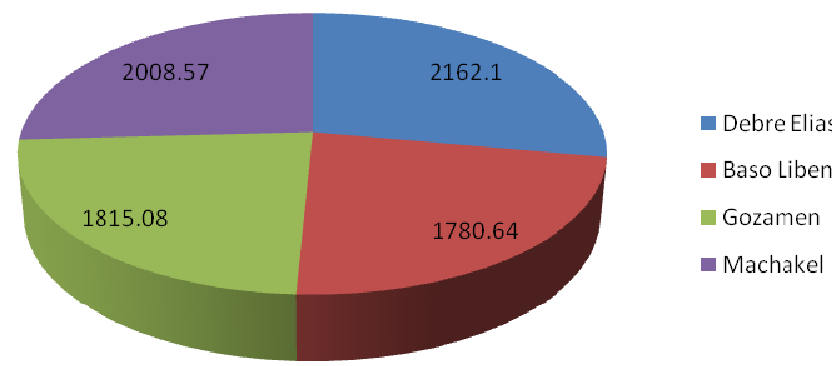

Figure 1. Level of income (ETB) from off-farm activities among districts.
The income level of households from off-farm activities was not significantly different across districts (Figure 1). In all districts, there are many households who earn income from off-farm sources.

However, when improved seed user and non user groups are considered, non-users were found to involve better in offfarm activities than those user groups. This resulted in significant mean differences in households' off-farm income level between the two categories of households.

The improved seed utilization intensity $(\mathrm{kg})$ across districts was found to be different among districts (Figure 2). The highest $(54.93 \mathrm{~kg})$ being in Debre Elias and the minimum $(39.56 \mathrm{~kg})$ in Gozamen. This variation arouse due to the wheat growing potentials of districts on and the income level (wealth status) of producer farmers. Information obtained from key informant farmers indicated that rich farmers have the ability to pay for the formal seed and adopt the package more quickly and utilize more intensely than poor households.

Note: The 2014 exchange rate of $1 \mathrm{ETB}=19 \mathrm{USD}$

Source: Survey result, 2014.

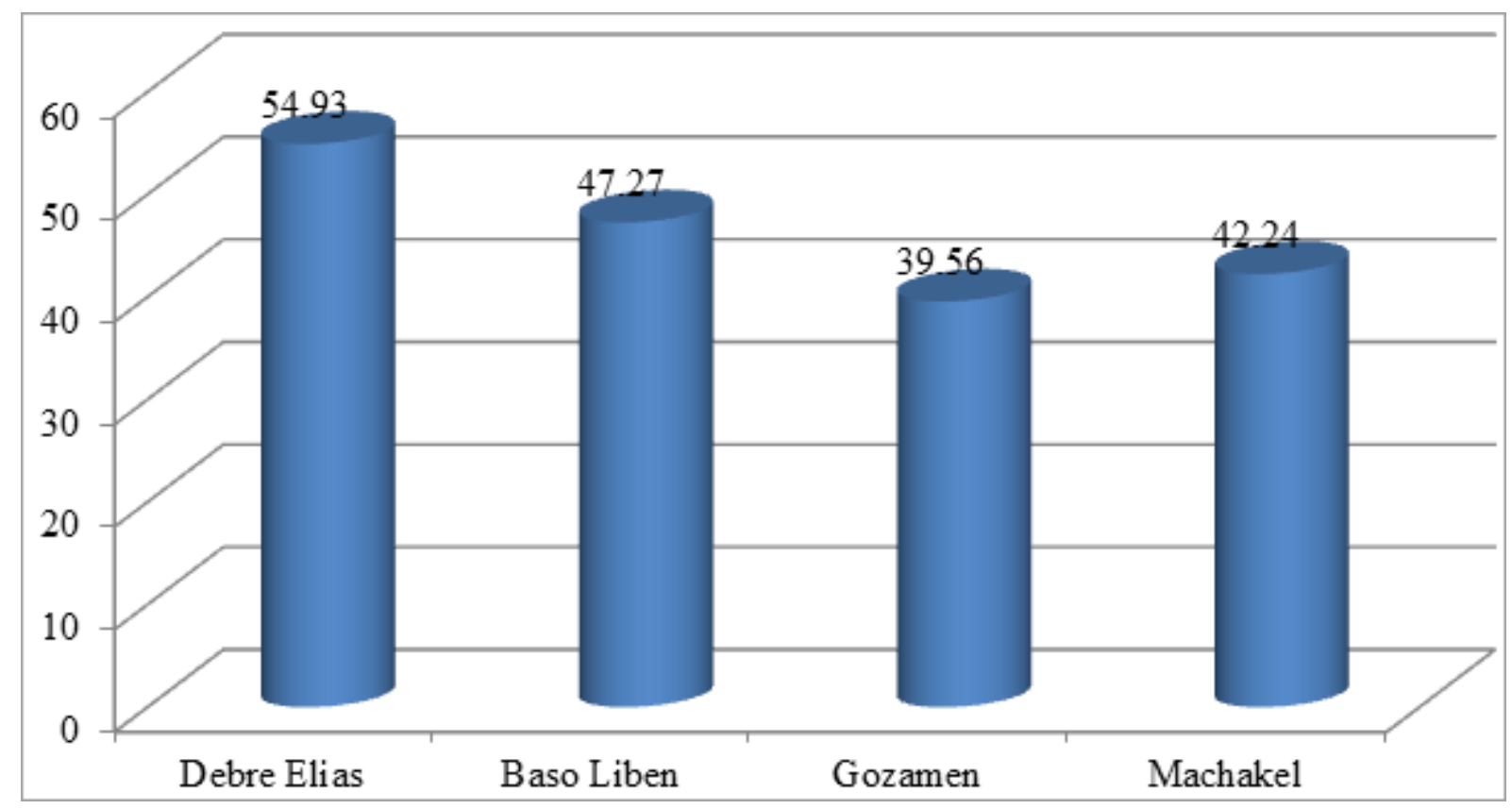

Figure 2. Amount of improved wheat seed $(\mathrm{kg})$ utilized across districts.

Source: Survey result, 2014

\subsection{The Seed System and its Impeding Factors}

There is a substantial improved seed demand not only bycommercialized farming but also for the subsistence households. It has been known that the conventional seed system is the ultimate origin of the modern seed system and the farmers' villages are prosperous in diverse indigenous seeds. However, it is embarrassed by various factors. The main factors impeding the smooth functioning of the seed sector in the study area are all interrelated and impose their roles directly or indirectly.

\subsubsection{Genetic Erosion}

Discussion made with key informants revealed that one of the common problems related with introduced varieties is radical decrement in quality attributes (agronomic) of crops. Crops that perform well in one year will exhibit yield decrement and become less resistant to various diseases and pest in the next year or after.

The major reasons attributed for the above problem include replacement of local varieties by genetically uniform high-yielding varieties, soil nutrient depletion and environmental changes and absence of concern to local crop 
varieties through community based seed programs.

The survey result revealed that the majority of crops that were native to the area disappeared because of genetic erosion (i.e., due to crossing with the newly introduced crop species). A farmer from the key informant group explained that none of the wheat cultivars previously (before 15 years) existed is available today. They were highly productive and preferable by the local community for making alcoholic drinks (locally consumable) like 'tella', 'areki' and 'injera'.

\subsubsection{Inadequate Seed Security Stocks}

At the national level, the mandate of genetic resource preservation is handled by the Ethiopian Institute of Biodiversity (EIB). However, this institute doesn't mainly focus on returning the lost cultivars to their original locations rather than its in-situ and ex-situ conservation strategies.

Cultivars may not necessarily disappear from a location for the occurrence of diseases or pests, rather due to farmers' cropping system. Farmers usually follow their neighbors' practices (try to cultivate similar varieties) and if by chance, all farmers fail to preserve seed of a particular variety; this crop will be missed from that location.

\subsubsection{Institutionalization of Seed Policies}

Current seed policies of Ethiopia are farmer based, rather, they act as institutions. The organization of the government and private seed enterprises are in a way that they stand and act as institutions rather than the situational needs of farmers. For instance, discussion made with key informants revealed that investigation and selection crop cultivars with desirable traits from farmers' fields should be a concern in order to empower producer farmers in using the right types of seeds.

Absence of participatory seed systems that involve farmers in the choice of a given crop variety had forced farmers to choose either the formal seed system (i.e., state owned and distributed via cooperative unions) or from the local system.Farmers 'involvement in the seed system help them acquire a strong trust up on the cultivars they previously knew. They reflect local experiences and knowledge in the choice of a right variety adaptable to the existing physical and agro ecological set up of the location.

As reported by Setimela, (2006), community based seed system leads to continuous exposure of farmers to new promising and preferred varieties in a way that stimulates the market, smallholder farmers should be informed of the advantages of buying fresh seed there will be strong linkages between national agricultural research and extension systems and seedcompanies (small or large-scale seed producers).

\subsubsection{Lack of Efficient Extension Services}

Currently, the agricultural extension policy is to reach at a quota of a specific expert for a particular expertise per Kebele Administration and now at least one expert is available at each Kebele Administration.Meanwhile, due to financial constraints, poor transportation and lack of incentives to motivate extension agents, extension services are relatively ineffective. The problem is aggravated particularly in remote Kebele Administrations where addressing villages is impossible due to lack of all weather road. This will lead to inadequate extension information which in turn will result in low adoption rates and intensity of improved seed use. Extension can raise awareness among farmers regarding the merits of the improved seed being introduced and work towards improving the ability of farmers to control the quality of seed.

Setimela et. al., (2006) reported that in areas where extension officers are present, it becomes easy to organize the farming community into groups for training and other events thereby there will be a possibility of delivering technical trainings to farmers through responsible stakeholders such as agricultural extension officers.

\subsubsection{Inefficient Seed Marketing Chains}

Commercial seed trade is an essential feature of industrial agriculture (Tripp 2001) and seed marketing is a vital link between the seed producers and the farmers who ultimately use the seeds.Seed production, proper and effective seed marketing and distribution are essential components of seed sector development.However, the existing actors in seed system market chainare performing inefficiently.

The only supply source of improved seeds is agricultural cooperatives depicting the existence of monopoly market system. Farmers do not have the power to bargain on seed prices. In order that the actual seed demand of farmers is fulfilled, there must be significant amount of hybrid seed for multiplication and distribution. Group discussion made with key informant farmers revealed that timely provision of the input through a single actor (cooperatives) is also a major problem that most farmers confronted with.

Dawit (2010) reported that seed marketing is carried out by cooperatives and farmer unions and this had been a constraint to the good performance of the private seed sector. The chain beginsfrom the Ministry of Agriculture and Rural Development (MoARD) that instructs the Ethiopian Seed Enterprise (ESE) on the type and quantity of seed to be delivered to cooperative unionswho in turn provide the seed to the primary cooperatives and farmers. This centralized system leaves cooperatives and farmers with relatively little flexibility in determining the type of seed they get or choice of suppliers.

On the basis of expensiveness, farmers' attitude and availability, there are two case scenarios in seed supply system. The first is the utilization of the locally available seed (informal) and the second is the improved (formal seed). Different studies indicated that the choice of the majority of Ethiopian farmers prefer utilization of the conventional seed system for various reasons. According to Abebe and Lijalem (2011), the preference by most farmers is due to its relatively cheapness and readily availabilityat the farmers' villagesjust at the time of demand,possibility of using seeds after testing on primary adopter farmers and its better reliability and sustainability than the newly introduced once.

The actual seed demands of each region and province/district in a given year are forecasted a year ahead and the cumulative needs of each region will be dispatched 
by the state seed enterprise via agricultural cooperative unions as depicted in Figure 3.

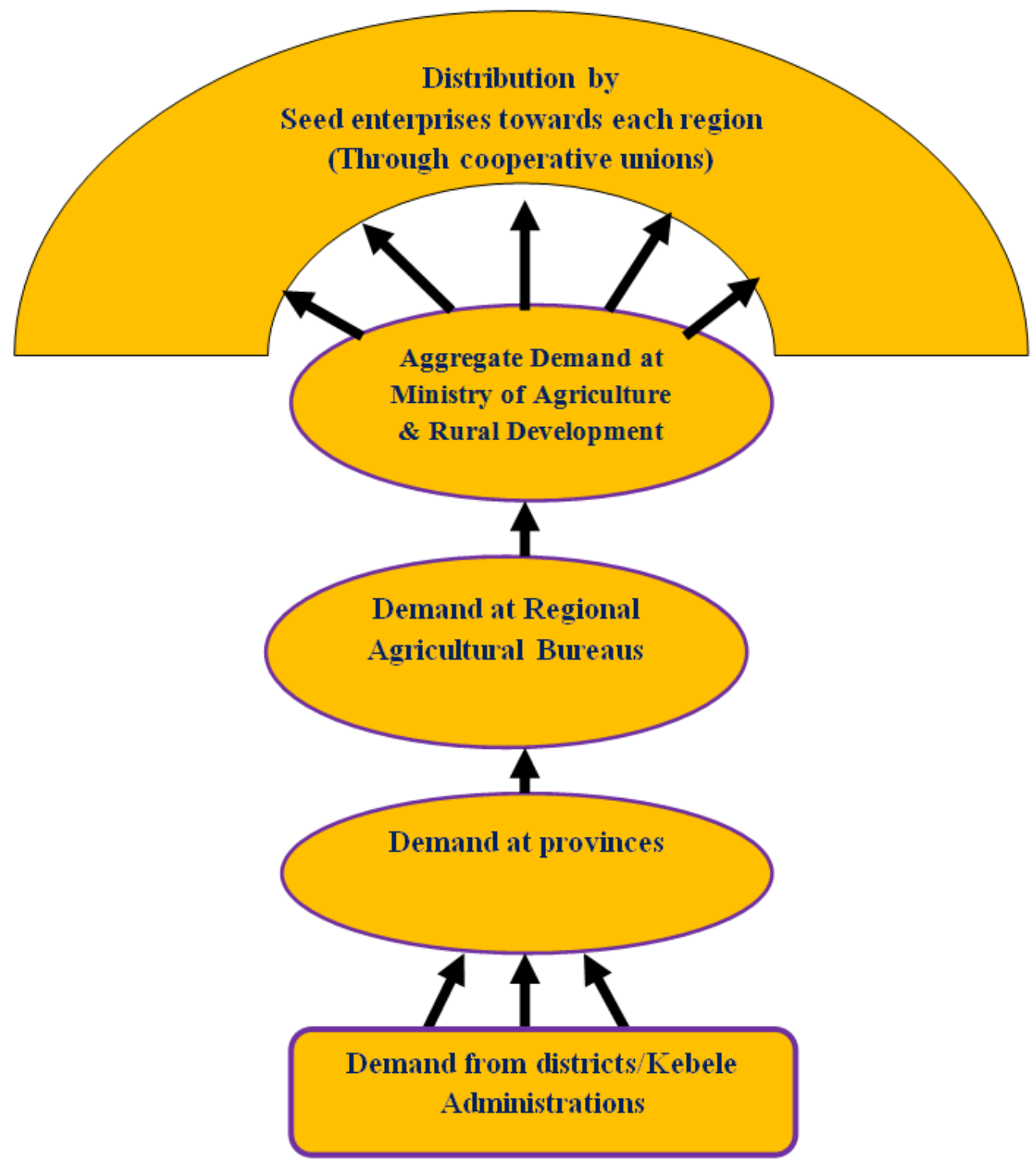

Source: Survey result, 2014.

Figure 3. Supply chains of the formal seed system.

\subsection{Factors Influencing Formal Seed Utilization and Intensity of Seed Use}

\subsubsection{Determinants for Improved Seed Use}

Land for Improved wheat (LAND)

The survey result indicated that there exists significantland size dynamism across user and non-user groups of households. It was hypothesized that the larger the plot size allocated for sowing improved wheat, the larger will be the volume of improved seed utilized. Land size affected the probability of improved seed utilization positively and significantly $(\mathrm{P}<0.01)$. It implies that a unitincrease in land sizeleads to an increase in the probability of improved seed utilization by $7.98 \%$ on average.

Discussion made with key informants indicated that plot size dynamism among producer farmers is the major cause of the variation in adoption of improved seeds. The larger the plot size that a household possess, the greater will be the tendency to involve in formal seed utilization (i.e., farmers will have better options to diversify crops on varying plots). Sain and Martinez (1999) indicated that the size of the farm positively affected the probability of adoption of improved seed as larger farm area is indicative of greater wealth and income which in turn are highly related to the possibility of acquiring more and better agricultural inputs.

Farming experience (FARMEXP)

The experience that farmers acquire through time is supposed to positively influence farmers' perception in adopting new technologies. The survey result indicated that older aged households were found to adopt and utilize formal seed system. Farming experience positively and significantly $(\mathrm{P}<0.1)$ affected the probability of improved seed utilization. 
A unit increase in the number of years of farming experience will lead to the probability of households' improved seed utilization approximately by $3.10 \%$.

The longer higher the number years that a household head engage in farming, the better will be his knowledge about production systems as he acquires experiences of land use systems, land suitability, soil characteristics and the right types of agricultural inputs to be used on a particular field.

\section{Age}

This is a determining factor for adoption of a technology. Older aged families are resistant to accept the new agricultural technology packages. The findings of this study showed that there was an inverse relationship with age of household heads and the probability of using improved seeds.
Thus, age caused a negative significant $(\mathrm{P}<0.01)$ effect on households' tendency of formal seed utilization. When the age of household heads increases by 1 year, there will be a decrease in the probability of improved seed use by $4.87 \%$ on average. This is because as household heads get older, they do not want to accept innovations as they expect production risks or high labor demand in using that technology.

In a pepper market supply study, Tesfaw (2013) found that age significantly affected the probability of farmers' involvement in product supply. The main reason attributed for this may be laborproductivity decreases with increasing age. Younger household heads showed a better tendency of adopting new agricultural packages than older one.

Table 5. Maximum likelihood (Probit) estimates of the Heckman Model.

\begin{tabular}{|c|c|c|c|c|}
\hline Variables & Coefficient & Standard Errors & t-ratio & MarginalEffect \\
\hline LAND & 10.4036 & 2.7117 & $3.84 * * *$ & 7.9813 \\
\hline TLU & 0.1635 & 0.1038 & 1.58 & 0.8843 \\
\hline FARINC & 0.1304 & 0.1068 & 1.22 & 0.3086 \\
\hline FAREXP & 0.0791 & 0.0468 & $1.69 *$ & 0.0309 \\
\hline DISRD & -0.0141 & 0.1112 & -0.13 & 0.0309 \\
\hline AGE & -0.0994 & 0.0374 & $-2.66 * * *$ & -0.0477 \\
\hline OXEN & 1.6379 & 0.6074 & $2.70 * * *$ & 6.0374 \\
\hline EDUC & -0.0380 & 0.1776 & -0.21 & -0.0990 \\
\hline OFFINC & -0.1419 & 0.1012 & $-1.40 * *$ & 0.1503 \\
\hline ACRDT & -0.3630 & 0.6894 & -0.53 & 0.0163 \\
\hline EXTEN & 0.0601 & 0.6371 & 0.09 & 23.2127 \\
\hline Constant & 0.8754 & 2.2537 & 0.39 & \\
\hline
\end{tabular}

Number of observations $=250$ Wald $\chi^{2}(11)=2594.57$ Censored Obs $=37$ Prob $>\chi^{2}=0.0000$

Uncensored observations $=213 \mathrm{Rho}=0.7368$ Sigma $=8.8909$

Note: * ** and $* * *$ indicate level of significance at $\mathrm{P}<0.1,0.05$ and 0.01 respectively

Source: Survey result, 2014

\section{OXEN}

Almost all sample households are subsistence producers who use oxen power to cultivate their plots. However, there was variations in the number of oxen owned by households and this variable caused positive and significant $(\mathrm{P}<0.01)$ effect on households' participation in using formal seeds. Similar findings were reported by Tesfaw (2013) that the larger the number of oxen owned by a farmer, the greater will be households' participation. From Table 5, one can see that a unit increase in the number of oxen will lead to an average increase in the probability of adoption by $6.04 \%$. This is because oxen are the only source of draft power used by small scale farmers.

Farmers owning relatively bigger plots practiced mixed farming than those who possess smaller plots. The trend is that in order to cultivate bigger plots, farmers increase the number of their oxen and this ultimately positively influenced the probability of involvement in formal seed utilization.

Income from off-farm activities (OFFINC)

Households sustain their lives by income from farming, off-farm activities or from both. Farmers who involved in off-farm activities showed lesser tendency of participation in formal seed supply. Income from off-farm activities negatively and significantly $(\mathrm{P}<0.05)$ influenced households involvement in formal seed utilization. The survey result showed that farmers who involve in off-farm activities such like petty trading are those who own smaller or no farm plots and earns their major income from such activities.

Such farmers usually rent out their land to other landless and rich farmers who own oxen. In this instance, they spent most of their time in non-farm activities which definitely results in limited participation in formal seed utilization.

\subsubsection{Factors Affecting the Intensity of Improved Seed Use Land size (LAND)}

This variable positively and significantly $(<0.01)$ affected the amount of formal seed utilized by households. This shows that an increase in plot size by 1 hectare results in an increase in the amount of formal seed utilized by $7.98 \mathrm{~kg}$ on average. The reason is attributed to the fact that the larger the plot size a household possesses, the larger will be the pieces of land allocated for improved seed and the higher the amount of improved seed sown. The land size dynamism is one of the major causes of variation in utilization as well as the amount of formal seed. An increase land size helps farmers implement crop diversification and adopt new agricultural packages.

Family size (FAMILSZ)

Family is the only source of labor for the farming 
community in the study area except few (only about 11\%) who demand non-family labor during critical working periods of the cropping season such. The result indicated that the amount of formal seed utilized by households was significantly $(\mathrm{P}<0.05)$ and positively influenced by family size. When the number members of a particular family increases by 1 , on average, the amount of improvedseed utilized by household heads increases by $88.43 \%$.

Discussion with key informant household heads revealed that the role of family labor become apparent and explicitly manifested at times of critical working periods such as sowing, weeding, harvesting and threshing. Availability of family labor is positively related with the wealth status of households. Households with big family size have better economic statusand can pay for new agricultural input utilization.

\section{Number of oxen (OXEN)}

Households owning relatively larger number of oxen were also found to possess bigger plots and better practice mixed cropping system than those owning smaller plots. The number of oxen significantly $(\mathrm{P}<0.01)$ and positively influenced the amount of formal seeds utilized (Table 6). The result showed that the amount of formal seeds utilized increases by $6.04 \mathrm{~kg}$ on average with an increase in the number of oxen by 1 .

Table 6. OLS estimates of factors affecting the amount of improved seed.

\begin{tabular}{lllll}
\hline Variables & Coefficient & Standard Errors & t-ratio & MarginalEffect \\
\hline LAND & 7.9813 & 2.2688 & $3.52^{* * *}$ & 7.9813 \\
FAMILSZ & 0.8843 & 0.3765 & $2.35^{* *}$ & 0.8843 \\
TLU & 0.2136 & 0.2328 & 0.92 & 0.2136 \\
FARMINC & 0.3086 & 0.6108 & 0.50 & 0.3086 \\
FARMEXP & 0.0309 & 0.0866 & 0.36 & 0.0309 \\
AGE & -0.0477 & 0.0721 & -0.66 & -0.0477 \\
OXEN & 6.0374 & 1.0391 & $5.81^{* * *}$ & 6.0374 \\
SEX & 5.6997 & 2.2873 & $2.49^{* *}$ & 5.6997 \\
EDUC & -0.0990 & 0.4337 & -0.23 & -0.0990 \\
OFFINC & 0.1503 & 0.2428 & 0.62 & 0.1503 \\
EXTFRQ & 23.2127 & 1.2262 & $18.93^{* * *}$ & 23.2127 \\
Constant & -9.7765 & 4.5229 & -2.16 & -9.7765 \\
Lambda & 6.5510 & 4.3935 & 1.49 & 6.5510 \\
\hline
\end{tabular}

Note: $* *$ and $* * *$ represent levels of significance at $\mathrm{P}<0.05$ and 0.01 respectively

Source: Survey result, 2014

Sex of household heads (SEX)

Male headed households were found to better adopt formal seed utilization than female headed households. The result indicated that sex positively and significantly $(\mathrm{P}<0.05)$ influenced the amount of formal seeds utilized.As a reality in most rural areas of Ethiopia, females are confined to routine home activities andhave limited participation in farming activities. The result indicated that female family heads either rent their whole plots to other farmers with informal contractual agreements or saw part of their plots by themselves. This resulted in significant variation in volume of improved seed utilization between male and female headed households.

As seen in the outcome equation of the Heckman twostage model (Table 6), the probability of household heads in being either male or female will result in a change in the quantity of formal seed utilization by $5.70 \mathrm{~kg}$. Hence male headed households better involve in farming activities and adopt production technologieswith input utilization better than female headed households.

Extension frequency (EXTFRQ)

In order that new agricultural packages are introduced and adopted, extension service has a fundamental role. The volume of formal seed utilized was affected significantly $(\mathrm{P}<0.01)$ and positively by the frequency of extension service delivered. A unit increment in the frequency of extension contact resulted in an increase in the amount of formal seed by 23.21 on average. Farmers who are close to the extension service showed a better tendency of adopting new technologies. They are willing to take production risks with expectation of high return from the new package they implement.

Tesfaye et. al., (2001) reported that farmers who were in frequent contact with experts andthose participating in demonstrations exhibited a higher probability of adopting an improved wheat variety.

\subsection{The Formal Seed Supply Chainand Market Linkages}

\subsubsection{Demand Forecast}

The actual needs of producer farmers from each district Based on the estimated annual seed demand of the regions, the Ministry of Agriculture and Rural Developmentdispatches the seed supply from the Ethiopian Seed Enterprise and Regional Seed Enterprises through cooperative unions (Dawit, 2010).

\subsubsection{Plant Breeding}

The currently existing strategy of seed system in Ethiopia forces the government owned (public) seed enterprises to focus on supplying breeder or foundation seeds and the privately owned seed enterprises to multiply the available basic seeds. The Ethiopian Seed Enterprise is the main state owned enterprise that multiplies and distributes all major crops (Dawit et al., 2008). 
The National Agricultural Research System (NRS) is responsible for plant breeding and raising of certified seeds. The NARS is comprised of the Ethiopian Institute of Agricultural Research, Regional Agricultural Research Institutes and Higher Learning Agricultural Institutes. They breed the desired crop varieties mainly targeting for improving desirable traits such as yield attributes, quality, tolerance to pests and diseases and tolerance to drought or moisture.

\subsubsection{Production of Certified Seeds}

Currently, the Ethiopian Seed Enterprise together with the Regional Seed Enterprises produces commercial seeds. Then, public or private seed enterprises multiply these basic seeds and distribute through cooperatives after certification.

\subsubsection{Marketing and Distribution of Certified Seeds}

Seeds produced by the public sector reach farmers via cooperatives. However, the distribution system is ineffective that open-pollinated seeds are often stockpiled in farmer unions and cooperatives (Dawit, 2010). Discussion made with key informants indicated that in addition to high prices, there is also a delay in time of arrival of improved seeds. This is because; there are no stakeholders responsible for seed delivery other than cooperatives.

\subsubsection{Adoption}

Seeds passing all the supply chain should reach all farmers. However, the extent to which farmers are willing to use a given variety depends on many factors. A household heads from the key informant group members revealed that despite their better yield advantage and other quality traits, improved seeds loss the desirable quality traits quickly, are more susceptible to weeds, pests and disease and their agronomic requirements are more tedious than locally available ones.According to Dawit (2010), though some farmers are enthusiastic in accepting new varieties, others refuse them and the rates of adoption are less than $50 \%$. The reason may be attributed to farmers' complains related with high seed prices, risks associated with newly introduced improved varieties and insufficient extension packages (Zewdie et. al., 2010).

However, in order that these newly introduced seeds are diversely utilized by all farmers, the role of extension services is found to be fundamental.

\section{Conclusion and Recommendations}

\subsection{Conclusion}

The existing seed system is currently a commercialized industry that is mainly driven by firms (cooperatives) which are primarily organized for profit making. This has imposed many challenges on farmers like high seed price, on time availability (supply) and quality problems.The existing seed multiplication systems are institutionalized rather than being participatoryand due to the absence of community-based seed multiplication systems (where there could have been a possibility of raising better performing cultivars from local landraces), some farmers are unwilling to take risks related with the utilization of newly introduced varieties. Despite the indispensable role of formal seeds, most farmers conserve seeds from their previous production. This is because; farmers have strong trust on the existing landraces that last relatively productive for many years despite

Farmers' tendency of utilizing formal seeds and the volume of formal seeds utilized was significantly influenced by many factors including size of land allocated for improved wheat, the number oxen, family size and the frequency of extension service delivery. In addition, several demographic and socio-economic factors were found to significantly influence both participation and intensity of improved seed utilized by households.

Because the national or regional seed demand is forecasted ahead for the coming year, sometimes there is a mismatch between the amount demanded and supplied.The real seed demand of farmers is thus known at the beginning of the production year at which farmers might have shifted from what they demanded in the previous year based on the existing agro-ecological and physical setups.

\subsection{Recommendations}

For its comparative advantage, farmers showed great tendency in adopting the improved seed utilization. However, many farmers fail to sow improved seeds every year.The last actors in the formal seed supply chain (before farmers) are only agricultural cooperatives. This has resulted in a monopoly market system in which farmers face problems of affording high seed prices on one hand and timely delivery of the seed on the other hand. Avoidance of monopolistic distribution of seeds through a single intermediary (only through agricultural cooperatives) by inviting other licensed bodies can lead towards competitive seed markets.

Land is one of the determining factors of formal seed use which is in turn a function of land use dynamics. Promoting crop diversification (multiple cropping) can enhance the utilization of formal seeds thereby creating the chance to allocate a plot for aparticular crop (use of multiple cropping systems) thereby increasing the probability of adoption of improved seeds.

As any agricultural package, the effect of extension frequency on adoption and the amount of seeds utilized was found to be highly significant. Thus, frequent delivery of extension services regarding formal seed utilization can help farmers participate more in improved seed utilization.

Due to limited participation of females in farm activities, intensity of formal seed utilization was significantly different between male and female headed households. This resulted from insufficient extension services (which could impose strong impact up on female farmers' psychological makeup) or financial deficits to utilize improved agricultural packages. This deserves urgent measure towards empowering females to participate and act equally with males through support with strong extension services, trainings and credit initiatives.

One of the reasons for the low rate of adoption of 
improved seeds is farmers' fear for the risk associated with newly introduced seed varieties. Thus, selection and development of local landraces through community based seed production techniques can be an efficient system in accelerating the seed supply.

\section{Acknowledgement}

I am indebted to Debre Markos University Research and Publication Directorate for granting me the budgetary need for this study. I owe special thanks to my beloved wife Rahel Zegeye for her absolute assistance. All development agents in the study districts, in the absence of whom, it would have been impossible to carry out this research, are acknowledged with special gratitude. My sincere thanks go to my colleagues (especially Mr. Seifu Birhanu) for their unreserved support. Finally, I warmly thank Mr. Yirgalem Eshetie and Mr. Tsegaye Molla, for their critical evaluation of the manuscript.

\section{References}

[1] Abebe Atilaw, Lijalem Korbu (2011). Recent Development in Seed Systems of Ethiopia. Debre Zeyit Research Centre, Ethiopia.

[2] Baffour Badu-Apraku, Robert Agyeibi Asuboah, Bamidele Fakorede, Baffour Asafo-Adjei(2014). Strategies for Sustainable Maize Seed Production in West and Central Africa. IITA, Nigeria. 140 pp.

[3] Bortei-Doku, Aryeetey E(1994).The significance of gender in seed transfer patterns amongfarmers in South-East Ghana. Institute of Statistical, Social and Economic Research (ISSER),University of Ghana, Legon, Ghana.

[4] Chapman R., R Tripp(2003). Changing Incentives for Agricultural Extension: A Review of Privatized Extension in Practice. Agricultural Research and Extension Network Paper No.132. London: UK Department for International Development (DFID)

[5] Crawford E W, T S Jayne, V AKelly (2006). Alternative Approaches for Promoting Fertilizer use in Africa. Agriculture and Rural Development Discussion Paper 22. Washington, D.C.: World Bank.

[6] Dawit Alemu, Shahidur Rashid, Rob Tripp (2010).Seed System Potential in Ethiopia Constraints and Opportunities for Enhancing the Seed Sector, Ethiopia.
[7] Dawit Alemu, Wilfred Mwangi, Mandefro Nigussie, David J.Spielman (2008). The maize seed system in Ethiopia: challenges and opportunities in drought prone areas. African Journal of Agricultural Research Vol. 3 (4). 305p.

[8] Heckman JJ (1979). Sample selection bias as a specification error, Econometrica. Pp.153-161

[9] IFPRI (International Food Policy Research Institute) (2011). Joint Estimation of Farmers' Stated Willingness to Pay for Agricultural Services.

[10] Rohrbach DD, Mtenga,K. M.Kiriwaggulu, S. Mwaisela (2002). Comparative study of threecommunity seed supply strategies in Tanzania, International Crops Research Institute for theSemi-arid Tropics, Bulawayo, Zimbabwe.

[11] Sain G, J Martinez(1999). Adoption and Use of Improved Maize by Small-Scale Farmers in Southeast Guatemala. CIMMYT Economics Paper 99-04. Mexico D.F.: CIMMYT.

[12] Setimela PS, P Kosina (2006). Strategies for Strengthening andScaling upCommunity-based Seed Production. Mexico, D.F.: CIMMYT.

[13] Setimela PS, E Monyo, M Bänziger (2004). Successful Community-Based Seed Production Strategies. Mexico, D.F.: CIMMYT.

[14] Tesfaw A(2013). Determinants of agricultural commodity market supply: a case study in the upper watershed of the Blue Nile, Northwestern Ethiopia. J. Agribus. Rural Dev. 4(30), 243-256.

[15] Tesfaye Zegeye, Girma Taye, D Tanner, HVerkuijl, Aklilu Agidie, W Mwangi (2001). Adoption of Improved Bread Wheat Varieties and Inorganic Fertilizer by Small-Scale Farmers in Yelmana Densa and Farta Districts of Northwestern Ethiopia. Mexico, D.F.: Ethiopian Agricultural Research Organization (EARO) and International Maize and Wheat Improvement Center (CIMMYT).

[16] Yonas Sahlu(2012). The Ethiopian Seed Quality Control System, Ethiopian Institute of Agricultural Research. FRG II Project Empowering Farmers' Innovation Series No. 3.

[17] Zewdie Bishaw, PC Struik, AJ Van Gastel (2010). Wheat Seed System in Ethiopia: Farmers' Varietal Perception, Seed Sources, and Seed Management, Journal of New Seeds, 11:4, 281-327, DOI: 10.1080/1522886X.2010.518302. 